\title{
The Effect of Temperature, Photosynthetic Photon Flux Density, and Photoperiod on the Vegetative Growth and Flowering of 'Autumn Bliss' Raspberry
}

\author{
J.G. Carew, ${ }^{1}$ K. Mahmood, J. Darby, ${ }^{2}$ P. Hadley, and N.H. Battey \\ Soft Fruit Technology Group, Centre for Horticulture and Landscape, The University of Reading, \\ Whiteknights, Reading, RG6 6AS, U.K.
}

\begin{abstract}
ADDITIONAL INDEX wORDS. Rubus idaeus, Richards function, growth modelling, crop prediction
ABSTRACT. The effects of temperature, photosynthetic photon flux density (PPFD) and photoperiod on vegetative growth and flowering of the raspberry (Rubus idaeus L.) 'Autumn Bliss' were investigated. Increased temperature resulted in an increased rate of vegetative growth and a greater rate of progress to flowering. Optimum temperatures lay in the low to mid $20^{\circ} \mathrm{C}$ range. Above this the rate of plant development declined. Increased $P P F D$ also advanced flowering. While photoperiod did not significantly affect the rate of vegetative growth, flowering occurred earliest at intermediate photoperiods and was delayed by extreme photoperiods. These responses suggest that there is potential for adjusting cropping times of raspberry grown under protection by manipulating the environment, especially temperature.
\end{abstract}

The raspberry (Rubus idaeus L.) has a clearly defined annual cycle of growth. In primocane fruiting cultivars, canes are produced in early spring and grow vegetatively until midsummer when floral primordia are initiated. These grow out to produce fruit in the autumn. In biennial fruiting cultivars flower initiation is delayed until autumn and, as a result, fruiting occurs in the canes' second year of development (Carew et al., 2000a). The timing of flower initiation depends on cultivar and location (Ourecky, 1976). This presumably reflects the fact that factors such as temperature, light and water availability, which obviously vary between sites, affect cane development (Hoover et al., 1989; Privé et al., 1993).

Growth rate in both biennial and primocane fruiting cultivars increases with temperature (Carew et al., 2000b; Kershaw, 1991; Ourecky, 1976; Williams, 1959a). For example, Ourecky (1976) found that as temperature increased from 13 to $25^{\circ} \mathrm{C}$ the plants' growth rate increased in 'Heritage'. Williams (1959b) observed even greater effects with the biennial fruiting raspberry 'Malling Promise'. A temperature of $24^{\circ} \mathrm{C}$ encouraged vigorous vegetative growth. However, $11^{\circ} \mathrm{C}$ caused canes to stop elongating beyond 1 to $2 \mathrm{~cm}$ in height, suggesting that dormancy had been induced. In previous work, Carew et al. (2000b) described the effect of temperature on node production in 'Autumn Bliss'. The rate of node production increased to an optimum of $\approx 22^{\circ} \mathrm{C}$. As temperature continued to increase, however, it became supraoptimal and node production slowed. This effect of high temperatures has also been observed in commercial production systems with the cultivar Heritage (Nonnecke and Taber, 1989).

Increasing temperatures also advance flowering (Kershaw, 1991; Lockshin and Elfving, 1981) and fruiting in primocane fruiting cultivars, but above an optimum temperature, fruiting is delayed (Carew et al., 2000b). In biennial fruiting cultivars, where flower initiation is more distinct from flowering and fruiting, the temperature at which flower initiation is delayed or prevented

Received for publication 10 June 2002. Accepted for publication 7 Jan. 2003. We acknowledge financial support from The University of Reading Research Endowment Trust Fund and Darby Brothers Farms Limited. We would like to thank Rex Brennan (SCRI, Dundee, Scotland) and Steve Adams (HRI, Wellesbourne) for their comments on the manuscript.

${ }^{1}$ Corresponding author

${ }^{2}$ Darby Brothers Farms Ltd., Bars Hall Farm, Basil Road, West Dereham, Kings Lynn, Norfolk, PE33 9RP, U.K. seems to be much lower than for primocane fruiting cultivars (Williams, 1959b).

While previous work has described the effects of temperature on fruiting (Carew et al., 2000b), the flowering response to temperature and the effects of light intensity and photoperiod have not been described. Williams (1959b) found that at 24 and $11{ }^{\circ} \mathrm{C}$, photoperiod did not affect development of the biennial fruiting cultivar Malling Promise. However, when an intermediate temperature was used $\left(17^{\circ} \mathrm{C}\right)$, a 9 -h photoperiod caused early cessation of cane growth when plants were 1 to $2 \mathrm{~cm}$ in height, but a photoperiod of $14 \mathrm{~h}$ supported vigorous growth. These data point to potentially important effects of photoperiod on raspberry. A quantitative analysis of the effects of temperature, photoperiod and light intensity, on raspberry growth and development is therefore required.

Without this quantitative approach, optimization of fruit production is not possible. This is especially the case where the aim is for an extension in cropping season. To satisfy demand for a 12-month supply of fruit, growers are now using heated polytunnels or glasshouses to extend cropping into the colder months (Allen and Raffle, 2000). In this context, the ability both to predict when fruiting will occur and to schedule flowering and fruiting become critical. The utility of this approach is shown for the strawberry by the model developed by Le Mière et al. (1998), which predicts strawberry yield and time of cropping based on the temperature that plants receive.

The two series of experiments described here were carried out to determine the effects of temperature, photosynthetic photon flux density $(P P F D)$ and photoperiod on cane growth and flowering in raspberry 'Autumn Bliss'. This information was used to examine the potential for manipulating environmental variables to schedule cropping in primocane fruiting raspberry cultivars.

\section{Materials and Methods}

Series 1: Photoperiod. Two experiments were conducted to determine the effect of photoperiod on the growth and flowering of 'Autumn Bliss'.

EXPERIMENTAL METHOD. One hundred and fifty plants of 'Autumn Bliss' were obtained from Darby Farms Brothers Ltd., Methwold, U.K. on 15 Oct. 1996 (Expt. 1) and on 28 Oct. 
1997 (Expt. 2). The canes were cut back to ground level on the following day and the root systems were placed in plastic bags and covered with peat-based potting compost (William Sinclair Horticulture Ltd., Lincoln, U.K.). Each group of roots was then transferred to cold stores at temperatures of $-0.3{ }^{\circ} \mathrm{C}$ (Expt. 1) and $-1.0{ }^{\circ} \mathrm{C}$ (Expt. 2) until the start of the experiments on 18 Dec. 1996 and 10 Feb. 1998, respectively. At these times the roots were potted into 3-L pots containing a peat-based potting compost (William Sinclair Horticulture Ltd., Lincoln, U.K.) and moved to a glasshouse with a mean diurnal temperature of 21.1 ${ }^{\circ} \mathrm{C}$ in Expt. 1 and a polytunnel with a mean diurnal temperature of $19.9^{\circ} \mathrm{C}$ in Expt. 2. In each case, the plants were allowed to develop until they had produced 8 to 14 nodes to ensure the effects of differences in times of shoot emergence were minimized. Then 48 plants were selected at random and transferred to the photoperiod-controlled glasshouse.

Experimental DeSign. Twelve plants were placed on each of four movable trolleys in a linear array of four photoperiodcontrolled glasshouse compartments. Plants remained in these light-tight compartments for $16 \mathrm{~h}$ from $1600 \mathrm{HR}$ each day. The compartments were maintained at $20 \pm 2{ }^{\circ} \mathrm{C}$. At $0800 \mathrm{HR}$ the trolleys were moved out of the compartments into a glasshouse with a heating set point of $15^{\circ} \mathrm{C}$, venting $4^{\circ} \mathrm{C}$ higher. Daylengths within each of the compartments were extended with three 60$\mathrm{W}$ tungsten bulbs and two $40-\mathrm{W}$ fluorescent tubes providing a light intensity of 3 to $5 \mu \mathrm{mol} \cdot \mathrm{m}^{-2} \cdot \mathrm{s}^{-1}$ measured at pot height. In all compartments the lights were switched on when the trolleys were returned to the compartments at $1600 \mathrm{HR}$ for a duration dependent on the desired photoperiod $(8,11,14$, and $17 \mathrm{~h})$. Thus, the plants remained for $8 \mathrm{~h}$ in the glasshouse at $\approx 15^{\circ} \mathrm{C}$ and $16 \mathrm{~h}$ in the compartments at $20^{\circ} \mathrm{C}$.

Measurements. After being placed in these treatments one shoot per plant was selected at random and allowed to develop; any other shoots were removed. Cane height was measured every two weeks and the time of terminal flower emergence was noted weekly. Final cane height was measured at anthesis of the terminal flower.

Series 2: PPFD AND TEMPERATURE. A series of experiments was initiated to determine the effect of temperature, PPFD and photoperiod on cane growth and flowering in the raspberry cultivar Autumn Bliss (Table 1).

Experimental DESIGN. Four experiments were carried out. The first three were carried out in five temperature-controlled glasshouse compartments arranged in a $3 \times 2$ block while in the fourth the plants were grown in a linear array of glasshouse compartments. In all experiments set point temperatures ranged between 6 and $26^{\circ} \mathrm{C}$. Plants were potted up and moved into the temperature treatments at four different times during the year (27 Feb. 1996, 18 Dec. 1996, 11 June 1997, 18 Jan. 1998) (Table 1). This allowed the plants to receive four different light intensities in each of the experiments due to the natural annual variation in light intensity. The same method was used for each experiment.

Experimental methoD. Plants of the cultivar Autumn Bliss were lifted from Darby Brothers Farms Ltd., Methwold, U.K. on 26 Feb. 1996, 15 Oct.

1996, 11 Dec. 1996

and 28 Oct. 1997

(Table 1). The plants were graded by eye, cut back to ground level, placed in bags and cold stored at
-1.0 to $0.5{ }^{\circ} \mathrm{C}$ until needed. The roots were then potted into $3-\mathrm{L}$ pots containing a peat-based potting compost (William Sinclair Horticulture Ltd., Lincoln, U.K.). In each experiment, 30 plants were moved into each glasshouse compartment and these were set to heat at $6,10,14,18,22$, and $26{ }^{\circ} \mathrm{C}$ and vent $4{ }^{\circ} \mathrm{C}$ higher. The actual temperatures were recorded every $30 \mathrm{~s}$ with a datalogger (Datataker DT500; Data Electronics, Letchworth, U.K.) using a four-wire platinum resistance probe and stored as hourly means. The temperature probes were situated in aspirated screens in each glasshouse compartment. Light intensities were also recorded every $30 \mathrm{~s}$ using tube solarimeters positioned $2 \mathrm{~m}$ above pot height and attached to the datalogger. The hourly average was then stored. In the first three experiments, three SON/T lamps provided a light intensity of $240 \mu \mathrm{mol} \cdot \mathrm{m}^{-2} \cdot \mathrm{s}^{-1}$ at ground level, measured using a quantum sensor placed at pot height, from 0600 to $0900 \mathrm{HR}$ and 1800 to $2200 \mathrm{HR}$ to extend the daylength to $16 \mathrm{~h}$. In the final experiment, the plants received only natural daylight. This means that in the final experiment, the effects were due to a combination of daylength and PPFD. Nutrients were supplied through Osmocote controlled release fertilizer $(14 \mathrm{~N}-4.2 \mathrm{P}-11.6 \mathrm{~K}$ + micronutrients) (Scotts U.K. Ltd., Nottinghamshire, U.K.) at a rate of $12 \mathrm{~g} /$ plant applied every 3 months (release rate, 3 to 4 months). Plants were sprayed for pests and diseases [primarily two spotted red spider mite (Tetranychus urticae)], as required using Pentac Aquaflo at $480 \mathrm{~g} \cdot \mathrm{L}^{-1}$ (Dow Agrosciences Ltd., Hertfordshire, U.K.) and Torque at $500 \mathrm{~g} \cdot \mathrm{L}^{-1}$ (Zeneca Agrochemicals, Surrey, U.K.).

Measurements. Once transferred to the glasshouse the plants were measured weekly. At these times, cane height and the time of terminal flower emergence were also recorded for each plant.

Data analyses - Vegetative Growth. The Richards function (Richards, 1959) was used to describe growth of the canes. It takes the form: $\log _{e} W=\log _{e} A+m \log _{e}\left(1+e^{(b+k t)}\right)$, where $\mathrm{W}=$ growth attribute, $\mathrm{A}=$ the final size or weight of the growth attribute (a constant), and $\mathrm{b}, \mathrm{k}, \mathrm{m}=$ constants.

Functions were fitted using the FITNONLINEAR subroutine of GENSTAT 5(Anon, 1993). Starting values with which to drive the model were calculated according to the Hadley method (Causton and Venus, 1981). While $\mathrm{k}$ and $\mathrm{m}$ cannot be interpreted on their own, the mean relative growth rate over the growth period can be calculated (Causton et al., 1978) as follows: weighted mean relative growth rate $=-\mathrm{k} /(-1 / \mathrm{m}+1)$.

Thus the Richards function can be used as a partly mechanistic model to determine the effect of environmental variables on plant growth. In addition, mean relative growth rate during the initial period of growth when the rate of increase in the natural log of cane height was constant (i.e., the period when cane height increased exponentially) was calculated from the gradient of the fitted relationship.

In this way, the summary statistics approach to the analysis of repeated measures was taken. This overcomes problems of correlation of data with time by calculating the rates at which data change over a period of time. In calculating the rates, nonhomogeneity of variance over time was taken into account by

Table 1. The schedule of experiments in series 2-the effect of PPFD and temperature.

\begin{tabular}{lllll}
\hline Experiment & 1 & 2 & 3 & 4 \\
\hline Lifting date & $26 \mathrm{Feb} .1996$ & 15 Oct. 1996 & 11 Dec. 1996 & 28 Oct. 1997 \\
Cold storage duration & N/A & $64 \mathrm{~d}$ & $181 \mathrm{~d}$ & $81 \mathrm{~d}$ \\
Planting date & $27 \mathrm{Feb} .1996$ & $18 \mathrm{Dec} .1996$ & $11 \mathrm{June} 1997$ & $18 \mathrm{Jan} .1998$ \\
Range of temperatures & $10,14,18,22,26^{\circ} \mathrm{C}$ & $10,14,18,22,26^{\circ} \mathrm{C}$ & $10,14,18,22,26^{\circ} \mathrm{C}$ & $6,10,14,18,22,26^{\circ} \mathrm{C}$ \\
Lighting & SON/T & SON/T & SON/T & None \\
\hline
\end{tabular}


transforming the data logarithmically (Mead et al., 1993).

FLOWERING. The number of accumulated degree days to flowering was estimated as the reciprocal of the gradient of the relationship between effective temperature and the reciprocal of the time to flowering or fruiting, using the method of Pearson et al. (1993). Effective temperature is defined as follows: $T_{e}=T_{o}-\mid T_{o}-T_{a} I$ assuming that $\mathrm{T}_{\mathrm{b}}<\mathrm{T}_{\mathrm{a}}<\mathrm{T}_{\mathrm{c}}$, where $\mathrm{T}_{\mathrm{e}}$ is the effective temperature, $\mathrm{T}_{\mathrm{o}}$ is the temperature at which rate of development is maximal, $\mathrm{T}_{\mathrm{a}}$ is the actual temperature theplants receive and $\mathrm{T}_{\mathrm{b}}$ and $\mathrm{T}_{\mathrm{c}}$ are the base and ceiling temperatures below and above which growth ceases. This method assumes that above the optimum temperature the rate of plant development declines linearly at the same but negative rate to that at suboptimal temperatures. The effect of PPFD in combination with effective temperature was calculated by multiple regression.

\section{Results}

Series 1: Photoperiod. In the first experiment, cane height of plants in all treatments increased approximately exponentially with time and there was no effect of photoperiod on growth (Fig. 1a). Although plants from the 8-h photoperiod treatment appeared to grow slightly slower than the other plants, this difference was not significant. In the second experiment, cane height also increased exponentially initially (Fig. 1b) but toward the end of the experiment growth slowed, presumably because the plants had begun to flower; again growth was not affected by photoperiod. The effect of photoperiod on the cane height of plants at flowering is shown in Fig. 2. In the second experiment, at intermediate photoperiods plants were generally shorter at flowering $(P<0.01)$. However, this was not the case in Expt. 1.
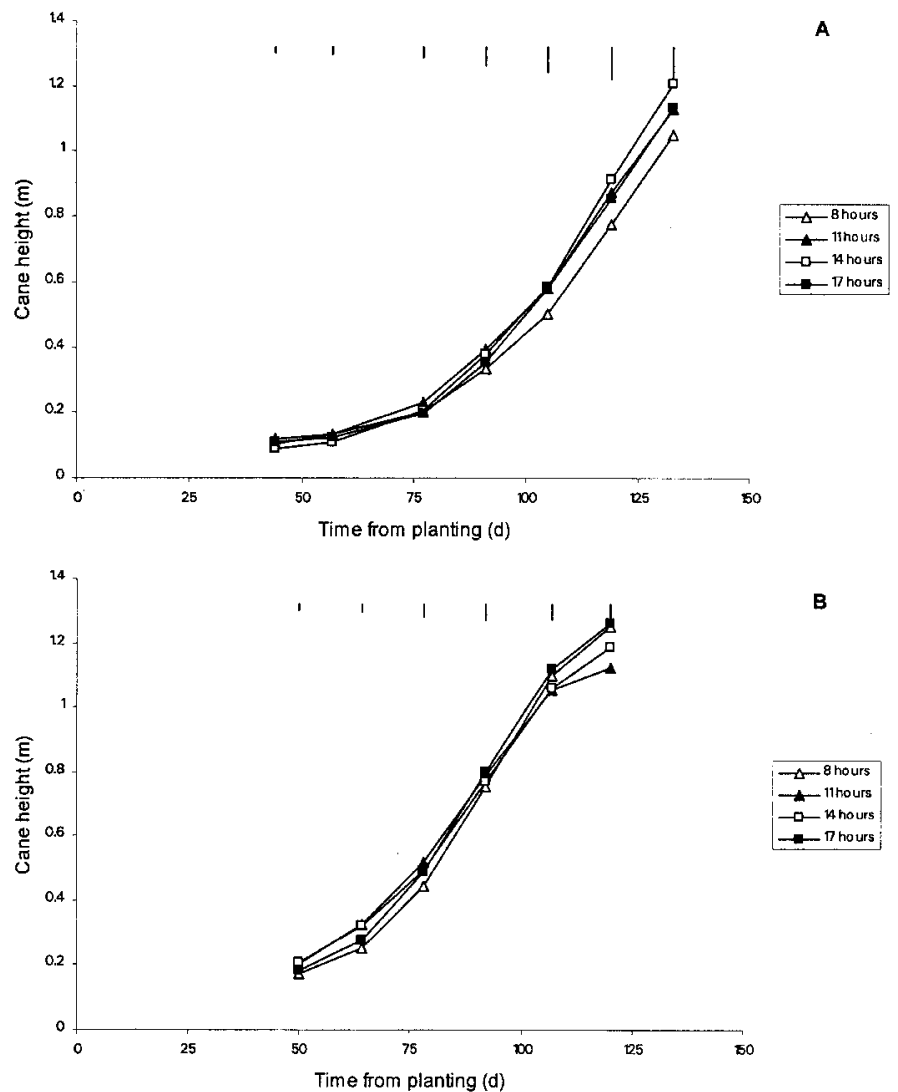

Fig. 1. Effect of photoperiod on increase in cane height of plants in the two photoperiod experiments. $(\mathrm{A}=$ Expt. 1 and $\mathrm{B}=$ Expt. 2$)$. Standard errors of the differences between means are shown.
Flowering was advanced by an increase in photoperiod from 8 to either 11 or $14 \mathrm{~h}(P<0.05$ for Expt. 1 and $P<0.01$ for Expt. $2)$. At longer photoperiods than this, time to flowering increased, although not significantly in Expt. 1. In general, therefore, flowering occurred in the shortest time under 11- or 14-h photoperiods. To quantify this, a regression analysis analogous to Pearson et al. (1993) was carried out to determine the exact optima (Fig. 3 ). This revealed that the rate of progress to flowering increased significantly to a calculated optimum photoperiod of 13.9 and 11.2 $\mathrm{h}$ in Expts. 1 and 2, respectively, and declined thereafter.

Series 2: PPFD AND Temperature. The data from the fourth experiment in this series (see Table 1) will be considered in detail first. Data from all four experiments will then be used to describe the effects of PPFD and temperature on flowering. In Expt. 4, growth of the raspberry canes occurred in three distinct phases, each of which was differently affected by temperature (Fig. 4). Initially, cane height increased exponentially from 75 to $125 \mathrm{~d}$ following planting as shown by the linear increase in the natural logarithm ( $\mathrm{ln})$ of cane height. Warmer temperatures resulted in a shorter duration of exponential growth and a greater rate of increase in the ln of cane height. Secondly, growth slowed toward the end of the experiment, the time at which this occurred being dependent on temperature. Growth of the plants at $24.5^{\circ} \mathrm{C}$ slowed earliest, after just less than $100 \mathrm{~d}$, but at temperatures above and below this, the cessation of growth was delayed. For example, at $9.9^{\circ} \mathrm{C}, \approx 200 \mathrm{~d}$ elapsed following the start of the experiment before growth slowed. Finally, cane extension ceased, presumably due to flowering of the apical meristem.

The effect of temperature on the relative growth rates calculated using the Richards function and the regression of ln cane height against time during the exponential growth phase (see Materials and Methods) is shown in Fig. 5. The mean relative growth rate (RGR) calculated from the Richards function was less than that calculated from the regression of ln cane height against time. This is because the RGR calculated from the Richards function is based on the complete growth curve while the regression method only takes into account the initial (exponential) phase of growth where RGR is at its maximum. In both cases though, relative growth rate increased linearly with temperature, reached a maximum and declined thereafter. A regression analysis analogous to that of Pearson et al. (1993) was carried out to determine the exact optimum temperatures. For the RGR calculated using the Richards function the optimum temperature was $24.1^{\circ} \mathrm{C}$ and from

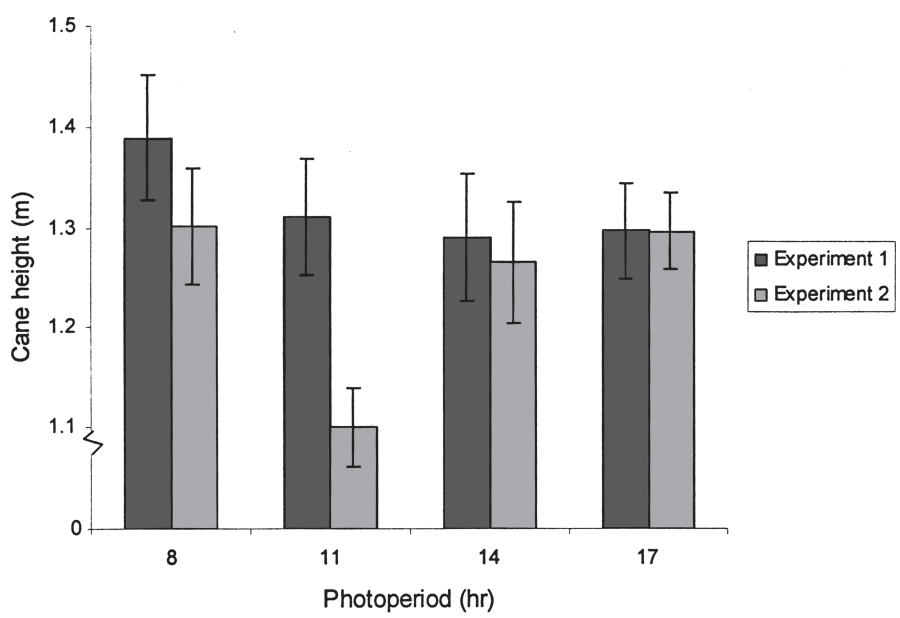

Fig. 2. The effect of photoperiod on the cane height of plants at anthesis of the terminal flower (standard error bars are shown). 


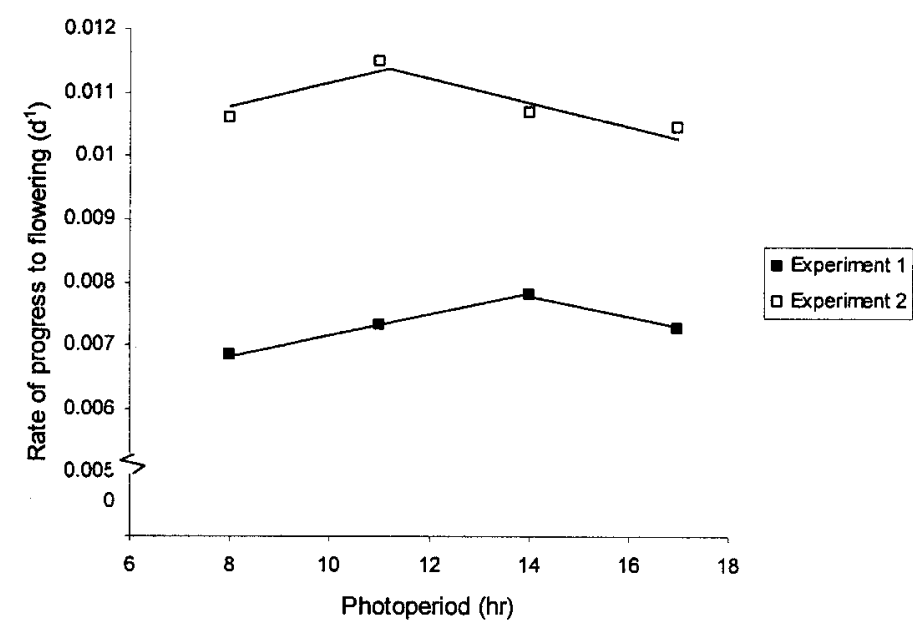

Fig. 3. The effect of photoperiod on the rate of progress to flowering of plants from the two photoperiod experiments. The lines were fitted by regression analysis of the mean rates of progress for each treatment based on 8 plants in Expt. 1 and 12 plants in Expt. 2. Expt. 1: the rates of progress to flowering = $0.00016 \mathrm{P}_{\mathrm{e}}+0.0055\left(R^{2}=0.99, \mathrm{df}=2\right)$ with standard errors of 0.0000022 and 0.0000089 , respectively. $\mathrm{P}_{\mathrm{o}}=13.9 \mathrm{~h}$. Expt. 2 : the rate of progress to flowering $=0.00019 \mathrm{P}_{\mathrm{e}}+0.0093\left(R^{2}=0.84, \mathrm{df}=2\right)$ with standard errors of 0.000058 and 0.00023 , respectively. $\mathrm{P}_{\mathrm{o}}=11.2 \mathrm{~h} . \mathrm{P}_{\mathrm{e}}=\mathrm{P}_{\mathrm{o}}-\mathrm{IP}_{\mathrm{o}}-\mathrm{P}_{\mathrm{a}} \mid$ where $0<\mathrm{P}_{\mathrm{a}}<24 . \mathrm{P}_{\mathrm{e}}=$ effective photoperiod, $\mathrm{P}_{\mathrm{a}}=$ actual photoperiod, $\mathrm{P}_{\mathrm{o}}=$ optimum photoperiod.

the regression of the ln of cane height against time, the optimum temperature was $24.0^{\circ} \mathrm{C}$.

Final cane height at the end of the experiment $\left(\log _{\mathrm{e}} \mathrm{A}\right.$ from the Richards function) increased with temperature to $18.0^{\circ} \mathrm{C}(P<$ 0.05 ) (Fig. 6). As temperature increased beyond $18^{\circ} \mathrm{C}$ the final plant size remained at $\approx 1.4 \mathrm{~m}$ although the plants in the $24.5^{\circ} \mathrm{C}$ treatment were slightly shorter.

The effect of temperature on the rate of progress to flowering for all four experiments in series 2 is shown in Fig. 7 and the response to temperature [calculated as an effective temperature (Pearson et al., 1993)] in combination with PPFD is shown in Fig. 8. The rate of progress to flowering increased linearly with temperature to an optimum of $24^{\circ} \mathrm{C}$, declining thereafter. No supraoptimal data are shown in Fig. 8 because the temperatures shown are effective temperatures rather than the actual temperatures. The rate of progress to flowering increased with increasing $P P F D$ from 9.8 to $17.7 \mathrm{~mol} \cdot \mathrm{m}^{-2} \cdot \mathrm{d}^{-1}$. Above this, the rate of progress to flowering appeared to decline although further investigation is required to quantify the effect of high $P P F D s$.

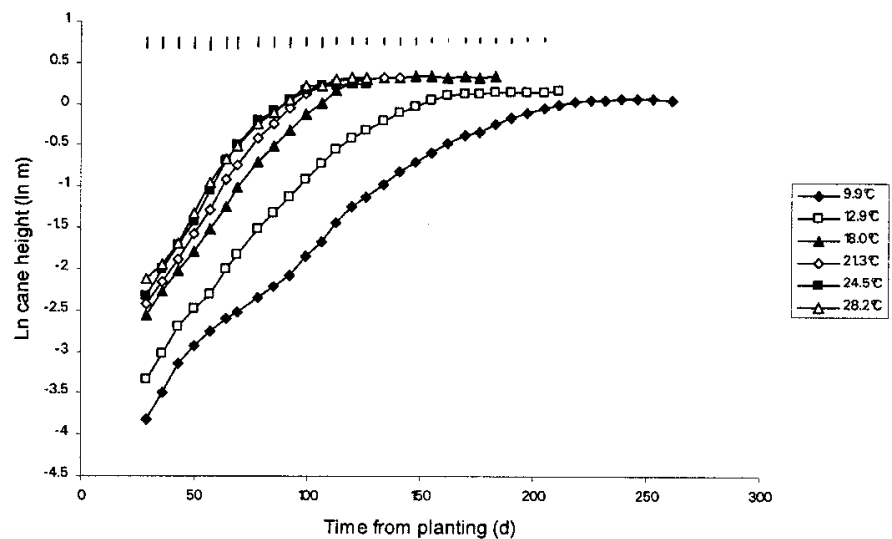

Fig. 4. The effect of temperature on the increase in the natural logarithm of cane height for plants planted on 18 Jan. 1998 (Expt. 4, series 2) (standard errors of differences between means are shown).
The relationship between the rate of progress to flowering and temperature was unaffected by $P P F D$ as the interaction between $P P F D$ and effective temperature was not significant. The predicted thermal time to first flowering decreased from 2451 to 1743 degree days as $P P F D$ increased from 9.4 to $19.4 \mathrm{~mol} \cdot \mathrm{m}^{-2} \cdot \mathrm{d}^{-1}$.

\section{Discussion}

Photoperiod had a significant effect on flowering of the primocane fruiting raspberry 'Autumn Bliss' $(P<0.05)$ whereas the effect of photoperiod on vegetative growth was not significant $(P>0.05)$. Current data suggest that as photoperiod increased from 8 to 11 or $14 \mathrm{~h}$, the time to flowering decreased, and as photoperiod increased further, flowering was delayed. Further information is required to demonstrate the response more clearly. However, what is clear is that the response was very different from that observed by Williams (1959b) for the biennial fruiting cultivar Malling Promise which flowered earliest under a short photoperiod.

High temperatures encouraged more rapid growth. Relative growth rate increased approximately linearly to about 24 ${ }^{\circ} \mathrm{C}$, declining thereafter. Several studies have also found shoot growth of raspberry to be enhanced by high temperatures (Kershaw, 1991; Ourecky, 1976; Williams, 1959a) but this is the first time that the relationship between temperature and growth rate has been defined.

The effect of temperature on the rate of progress to flowering was similar to its effect on the rate of vegetative growth. As temperature increased from $9.9^{\circ} \mathrm{C}$ to $24^{\circ} \mathrm{C}$, there was an increase in the rate of progress to flowering (and therefore a decrease in time to flowering) in each experiment. For example, in Expt. 4 series 2 , this resulted in a decrease in the time to flowering of $\approx 3$ months for a $15^{\circ} \mathrm{C}$ increase in temperature. Kershaw (1991) also found that high temperatures reduced the time to flowering in 'Autumn Bliss', and Lockshin and Elfving (1981) found a

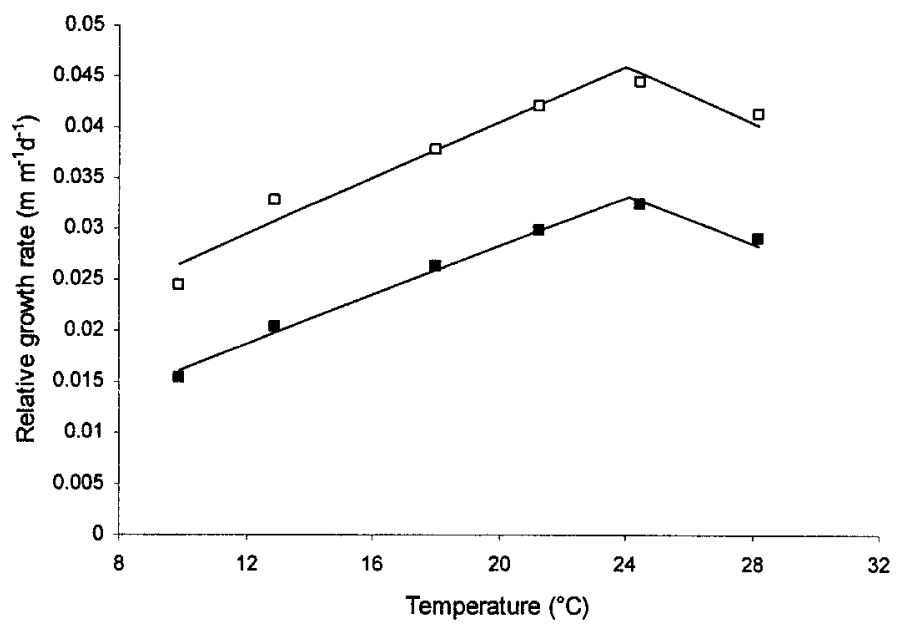

Fig. 5. The effect of temperature on the relative growth rates of plants in Expt. 4, series 2, calculated using the regressions of ln cane height against time (open symbols) and the Richards function (closed symbols). The Richards function allows the mean relative growth rate over the complete growth period to be calculated (Causton et al., 1978) as follows: Weighted mean relative growth rate $=-\mathrm{k} /(-1 / \mathrm{m}+1)$. The lines were fitted by regression analysis where RGR from Regression $=0.0014 \mathrm{~T}_{\mathrm{e}}+0.013\left(R^{2}=0.96, \mathrm{df}=4\right)$ with standard errors of 0.00014 and 0.0016 , respectively. $\mathrm{T}_{\mathrm{o}}=24.0^{\circ} \mathrm{C}, \mathrm{T}_{\mathrm{b}}=-9.3{ }^{\circ} \mathrm{C}$. RGR from the Richards function $=0.0012 \mathrm{~T}_{\mathrm{e}}+0.0043\left(R^{2}=0.99, \mathrm{df}=4\right)$ with standard errors of $5.61 \times 10^{-5}$ and 0.0016 , respectively. $\mathrm{T}_{\mathrm{o}}=24.1^{\circ} \mathrm{C}, \mathrm{T}_{\mathrm{b}}=-3.6^{\circ} \mathrm{C} . \mathrm{T}_{\mathrm{e}}=$ $\mathrm{T}_{\mathrm{o}}-\left|\mathrm{T}_{\mathrm{o}}-\mathrm{T}_{\mathrm{a}}\right|$ where $\mathrm{T}_{\mathrm{c}}>\mathrm{T}_{\mathrm{a}}>\mathrm{T}_{\mathrm{b}}, \mathrm{T}_{\mathrm{c}}=$ ceiling temperature, $\mathrm{T}_{\mathrm{a}}=$ actual temperature and $\mathrm{T}_{\mathrm{b}}=$ base temperature. 


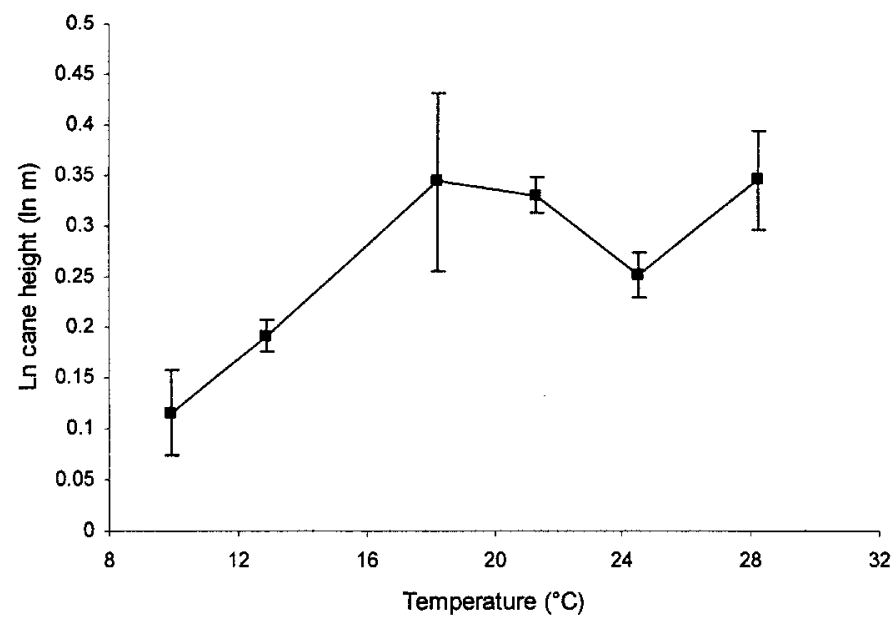

Fig. 6. The effect of temperature on the final ln cane height of plants at flowering in Expt. 4, series 2 (fitted asymptotes from the Richards function $-\log _{\mathrm{e}} \mathrm{A}$ ). Standard error bars are shown.

similar effect in the primocane raspberry 'Heritage' but again the relationship between temperature and flowering has not previously been defined.

The reduction in final cane height at low temperatures was probably a result of vernalization acting at these temperatures (Carew et al., 2001). Flowering still took longer than at higher temperatures because the plants grew at a slower rate. Temperature therefore acted in two ways, by affecting both the timing of flower induction and the rate of cane growth.

Greater PPFDs also increased rate of progress to flowering. As a result, the number of accumulated day degrees to flowering declined from 2451 to 1743 with an increase in PPFD of $10 \mathrm{~mol} \cdot \mathrm{m}^{-2} \cdot \mathrm{d}^{-1}$. Clearly plants flowered earlier under increased PPFDs irrespective of the temperature regime.

In the experiments described here, there was a curvilinear relationship between $P P F D$ and the rate of progress to flowering, suggesting that as $P P F D$ increases above a specific point, the rate of progress to flowering will actually decrease. It is more likely though that above a specific point, $P P F D$ will not affect flowering time or its response to temperature (Adams et al., 1997; Pearson et al., 1993). Clearly, the function needs modification once sufficient data are available and the effect of a greater range of PPFDs is known.

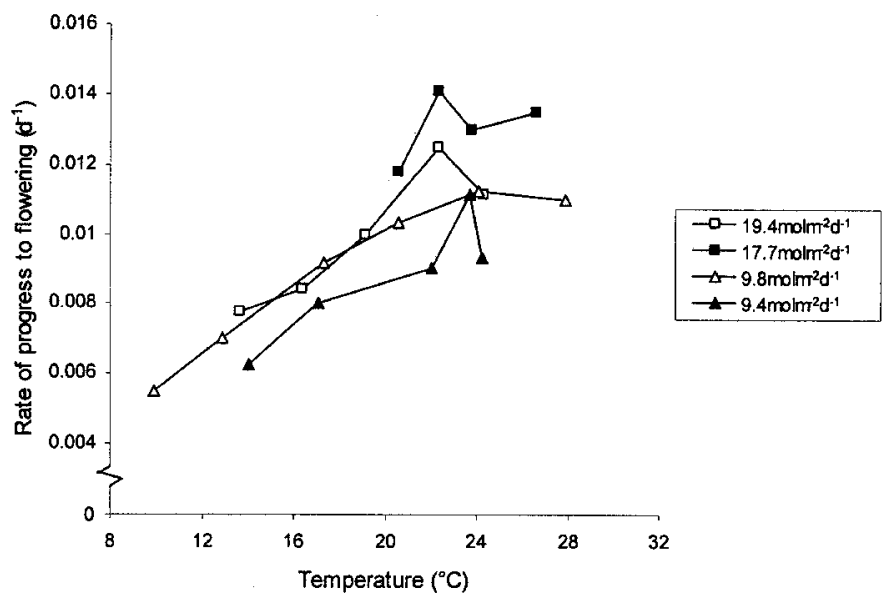

Fig. 7. The effect of temperature in combination with $P P F D$ on the rate of progress to flowering of plants in all four experiments in series 2 .
The range of thermal time required for flowering (1743 to 2451 degree days) at the PPFDs experienced here is very different from other reports for the primocane fruiting raspberry. For instance, Kershaw (1991) indicated a temperature sum of 1109 degree days for 'Autumn Bliss' based on a base temperature of $5.84^{\circ} \mathrm{C}$. This can partly be explained by differences in the base temperature selected which will cause the value of thermal time to flowering to vary. However, there is also real variation in thermal time to flowering/fruiting between and within cultivars depending on other environmental factors. For example, Hoover et al. (1989) found differences as great as $25 \%$ in the number of accumulated day degrees before fruiting in 'Redwing' and 'Heritage' when these were grown at different sites across the United States. Values ranged from 1443 to 2033 degree days for 'Redwing' and from 1453 to 2033 degree days for 'Heritage'. In these examples a base temperature of $5^{\circ} \mathrm{C}$ was assumed. Presumably, varying light conditions would have contributed to these differences.

Raspberry cultivars are categorized as either biennial or primocane fruiting. The basis for this categorization is their time of fruiting, either in the first or second year of cane growth. However, this seems to reflect their time of flower initiation rather than an inherent need to fruit on first or second year canes. In general primocane fruiting cultivars initiate flowers earlier in autumn than biennial cultivars (Waldo, 1933; Williams, 1959b) at times of the year when temperatures tend to be higher. The experiments described here and those reported elsewhere (Kershaw 1991; Lockshin and Elfving, 1981; Vasilikakis et al., 1979; Williams, 1959b) have shown that primocane fruiting cultivars flower and fruit under higher temperatures and longer daylengths than biennial fruiting cultivars.

It seems likely therefore, that because the timing of flower initiation in a particular cultivar is determined by temperature and photoperiod, raspberry cultivars cannot always be definitely classified as either biennial or primocane fruiting (Carew et al.,

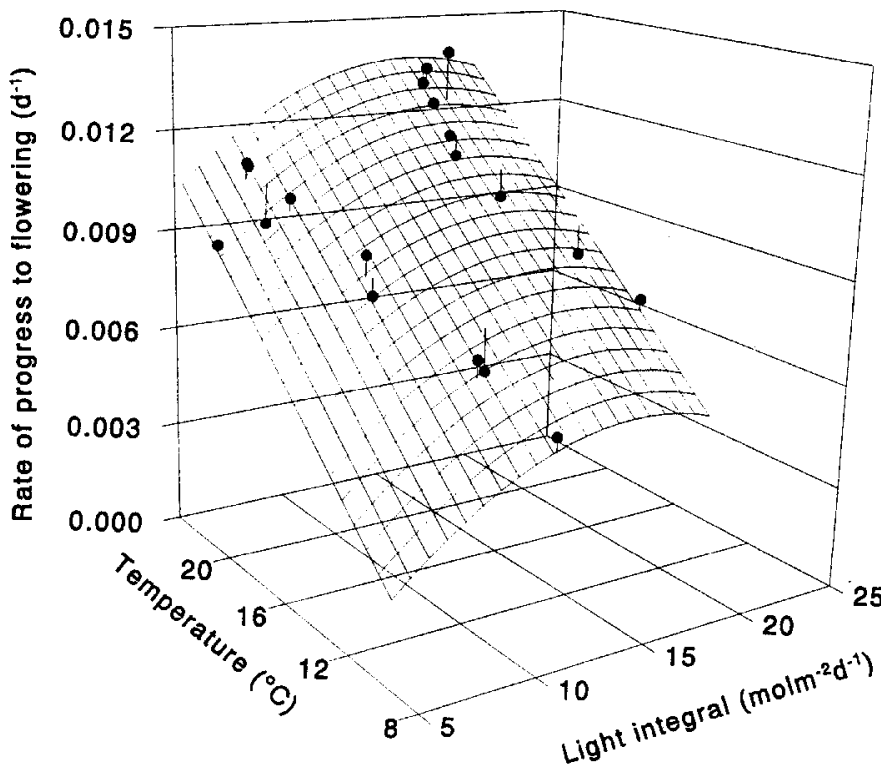

Fig. 8. The fitted relationship between light, effective temperature and rate of progress to flowering for the complete data set was calculated by regression using the modified effective temperature regression method of Pearson et al. (1993). The temperatures shown are effective temperatures as the regression was based on individual hourly averages and not the average temperatures from planting to flowering. The rate of progress to flowering $=0.00058 \mathrm{~T}_{\mathrm{e}}+$ $0.000913 \mathrm{~L}-0.000028 \mathrm{~L}^{2}-0.00768\left(R^{2}=0.91\right)$. Standard errors are 0.000046 , $0.00029,0.000011$ and 0.0021 , respectively. $T_{e}=T_{o}-I T_{o}-T_{a} I$ where $T_{c}>T_{a}>T_{b}$, $\mathrm{T}_{\mathrm{c}}=$ ceiling temperature, $\mathrm{T}_{\mathrm{a}}=$ actual temperature and $\mathrm{T}_{\mathrm{b}}=$ base temperature. 
2000a). Cultivars which flower earlier at higher temperatures, such as 'Autumn Bliss', are classified as primocane fruiting because they would flower in summer and fruit during autumn. Those with requirements for short photoperiods and low temperatures, however, initiate flowers too late in the autumn to grow out and form fruit until spring the following year. But cultivars that flower under intermediate temperatures and photoperiods behave in a fashion intermediate between biennial and primocane fruiting cultivars and so produce a proportion of fruit during autumn and a proportion during spring the following year, as happens in the cultivar Glen Moy (Carew et al., 2000a; Ourecky, 1976). Therefore, a more appropriate way to categorize cultivars would be to use the time of flower initiation or the temperature/light requirements for flower initiation rather than whether the plants fruit on first or second year canes.

Sensitivity of raspberry cultivars to environmental variables, especially temperature and photoperiod should allow growers to manipulate cropping patterns. For example, in the United Kingdom a major interest is to extend raspberry cropping beyond the natural season (May to November) (Allen and Raffle, 2000). However, practical experience suggests that this may not be straightforward. Nonnecke and Taber (1989) used row covers on cultivar Heritage to increase temperature but they did not alter fruiting times. Raffle (1998) also found no effect of covering with fleece during March and April on the time of cropping in 'Autumn Bliss'. Novel technologies, especially methods of protected cropping, will only work efficiently if they are designed with the environmental responses of the plant in mind. To encourage plants to fruit at specific times of the year, temperature regimes could be planned in advance based on the flowering and fruiting response of the plants to photothermal environment.

In conclusion, vegetative growth and flowering of 'Autumn Bliss' are both significantly affected by photoperiod, temperature and $P P F D$. Cane growth rate increases linearly to an optimum temperature of $\approx 24^{\circ} \mathrm{C}$ and declines progressively at higher temperatures. The rate of progress to flowering shows a similar response, increasing linearly to an optimum of $\approx 24$ ${ }^{\circ} \mathrm{C}$. The rate of progress to flowering also increases with higher $P P F D$ s. This detailed information indicates great sensitivity to temperature and light, and provides background data needed to schedule cropping of raspberry. However, more work is required to understand the effect of environmental variables on development of other cultivars so that technologies can be optimized for individual cultivars.

\section{Literature Cited}

Adams, S.R., S. Pearson, and P. Hadley. 1997. The effects of temperature, photoperiod, and light integral on the time to flowering of pansy cv. Universal Violet (Viola $\times$ wittrockiana Gams.). Ann. Bot. London 80: 107-112.

Allen, J. and S. Raffle. 2000. Raspberries under cover. Grower 3 Feb. 2000. p. 12-14.

Anon. 1993. Genstat 5 release 3 reference manual. Clarendon Press,
Oxford, U.K.

Carew, J.G., T. Gillespie, J. White, H. Wainwright, R. Brennan, and N.H. Battey. 2000a. The control of the annual growth cycle in raspberry. J. Hort. Sci. Biotechnol. 75:495-503.

Carew, J.G., P. Hadley, J. Darby, and N.H. Battey. 2000b. The effect of temperature on the vegetative growth and reproductive development of the primocane fruiting raspberry cv. Autumn Bliss. Acta Hort. 505: 185-190.

Carew, J.G., K. Mahmood, J. Darby, P. Hadley, and N.H. Battey. 2001. The effects of low temperatures on the vegetative growth and flowering of the primocane fruiting raspberry 'Autumn Bliss'. J. Hort. Sci. Biotechnol. 76:264-270.

Causton, D.R., C.O. Elias, and P. Hadley. 1978. Biometrical studies of plant growth. I. The Richards function and its application in analysing the effects of temperature on leaf growth. Plant Cell Environ. 1:163-184.

Causton, D.R. and J.C. Venus. 1981. The biometry of plant growth. Edward Arnold, London, U.K.

Hoover, E., J. Luby, D. Bedford, M. Pritts, E. Hanson, A. Dale, and H. Daubeny. 1989. Temperature influence on harvest date and cane development of primocane fruiting red raspberries. Acta Hort. 262:297-303.

Kershaw, C. 1991. The effect of temperature on the rate of shoot development in the raspberry (Rubus idaeus L.) cultivar Autumn Bliss. PhD diss. Wye College, Univ. London.

Le Mière, P., P. Hadley, J. Darby, and N.H. Battey. 1998. The effect of thermal environment, planting date and crown size on growth, development and yield of Fragaria $\times$ ananassa Duch. cv. Elsanta. J. Hort. Sci. Biotechnol. 73:786-795.

Lockshin, L.S. and D.C. Elfving. 1981. Flowering response of 'Heritage' red raspberry to temperature and nitrogen. Hortscience 16:527-528.

Mead, R., R.N. Curnow, and A.M. Hastead. 1993. Statistical methods in agriculture and experimental biology. $2^{\text {nd }}$ ed. Chapman and Hall, London, U.K.

Nonnecke, G.R. and H.G. Taber. 1989. Effects of row cover on vegetative and reproductive growth of Heritage red raspberry. Acta Hort. 262:391-394.

Ourecky,D.K. 1976. Fall-bearing red raspberries, their future and potential. Acta Hort. 60:135-144.

Pearson, S., P. Hadley, and A.E. Wheldon. 1993. A reanalysis of the effect of temperature and irradiance on the time of flowering of chrysanthemum (Dendranthema grandiflora ). J. Hort. Sci. 68:89-97.

Privé, J-P, J.A. Sullivan, J.T.A. Proctor, and O.B. Allen. 1993. Climate influences vegetative and reproductive components of primocane-fruiting red raspberry cultivars. J. Amer. Soc. Hort. Sci. 118:393-399.

Raffle, S.M. 1998. Practical ways of spreading the season of Autumn Bliss raspberries. Proc. of the ADAS/HRI/EMRA Soft Fruit Conf. 1998, Ashford, U.K.66-70.

Richards, F.J. 1959. A flexible growth function for empirical use. J. Expt. Bot. 10:290-300.

Vasilikakis, M.D., B.E. Struckmeyer, and M.N. Dana. 1979. Temperature and development of red raspberry flower buds. J. Amer. Soc. Hort. Sci. 104:61-62.

Waldo, G.F. 1933. Fruit bud formation in brambles. Proc. Amer. Soc. Hort. Sci. 30:263-267.

Williams, I.H. 1959a. Effects of environment on Rubus idaeus L. III Growth and dormancy of young shoots. J. Hort. Sci. 34:210-218.

Williams, I.H. 1959b. Effects of environment on Rubus idaeus L. IV Flower initiation and development of the inflorescence. J. Hort. Sci. 34:219-228. 